\title{
Competencia morfogénica de embriones maduros de Pinus radiata cultivados in vitro y su relación con la posición del cono en el árbol
}

\author{
Morphogenic competence of mature in vitro cultured Pinus radiata embryos \\ and their relation with cone position in the tree
}

\author{
Manuel Sánchez-Olatea*, Jaime Zapata Valenzuela ${ }^{\mathrm{b}}$, Patricia Sáez Delgado ${ }^{\mathrm{a}}$, Darcy Ríos Leala, \\ Scarlette Spiercolli Henríquez ${ }^{\mathrm{a}}$, Carolina Alvarez Maldinia ${ }^{\mathrm{a}}$, Catherine Delaveau ${ }^{\mathrm{a}}$, Guillermo Pereira Cancino ${ }^{\mathrm{a}}$ \\ *Autor de correspondencia: aniversidad de Concepción, Facultad de Ciencias Forestales, Laboratorio Cultivo de Tejidos, \\ Centro de Biotecnología, Victoria 631, Concepción, Chile, tel.: 41-2204906, fax 41-2255164, msanche@udec.cl \\ bBioforest S.A., Concepción, Chile.
}

\section{SUMMARY}

The micropropagation of zygotic material collected from adult trees constitutes an important alternative in massive propagation of select phenotypes, appropriate for cloning programs implemented by forest companies. Using this technique, embryonic axes extracted from lignified cones located at different heights in the trees (basal, medial and apical zones) where in vitro introduced, with the objective of analyzing the possible relation between the physiological state of the forming tissue and the response obtained in the micropropagation of mature Pinus radiata embryos. Embryos obtained from cones located in the basal zone of the donor tree, demonstrated the best results in regards to germination (95\%), survival (100\%), microshoot proliferation (1.7 buds/microstems) and microshoot elongation $(25 \mathrm{~mm})$, which allowed to establish a relation between the development states of the explants and their response in artificial in vitro conditions, supplying background information for the implementation of a classification criteria of the collected material to be used in tissue cultures, due to the variable responses obtained according to the origin of the embryos from donor trees.

Key words: Pinus radiata, zygotic embryos, reinvigoration, physiologic age.

\section{RESUMEN}

La micropropagación de material embrionario colectado de árboles adultos constituye una alternativa importante en la propagación masiva de fenotipos selectos, adecuados para los programas de clonación implementados por las empresas forestales. Utilizando esta técnica, ejes embrionarios maduros extraídos desde conos lignificados ubicados a diferentes alturas en el árbol (zonas basal, media y apical) fueron introducidos in vitro con el objeto de analizar la posible relación entre el estado fisiológico del tejido formador y la respuesta obtenida en la micropropagación de embriones maduros de Pinus radiata. Embriones obtenidos desde conos ubicados en la zona basal del árbol donador mostraron los mejores resultados en germinación (95\%), supervivencia (100\%), proliferación de microtallos (1,7 yemas/microtallos) y longitud de microtallos $(25 \mathrm{~mm})$. Ello permitió establecer una relación entre el estado de desarrollo del explanto y su respuesta en condiciones artificiales de cultivo in vitro, entregando antecedentes para la implementación de criterios de clasificación del material colectado para ser utilizado en cultivo de tejidos debido a la respuesta variable según el origen de los embriones desde el árbol donador.

Palabras clave: Pinus radiata, embriones zigóticos, revigorización, edad fisiológica.

\section{INTRODUCCIÓN}

En árboles, el término madurez se refiere a los procesos asociados a la edad y que influyen en los cambios en el desarrollo del individuo, afectando negativamente su capacidad regenerativa vía asexual (Fraga et al. 2002, Borja et al. 2004). En general, se habla de tres procesos que explican la madurez en plantas leñosas: envejecimiento cronológico, referido a cambios expresados en función del tiempo; envejecimiento ontogénico, relacionado a la transición gradual e irreversible regulada bajo control ge- nético, siendo la floración un marcador morfológico que indica el paso desde un estado juvenil hacia adultez; y envejecimiento fisiológico, asociado a la pérdida de vigor causada por cambios hormonales y condiciones nutricionales y ambientales que se relacionan al incremento del tamaño y complejidad del árbol (Pierik 1990, Russell et al. 1990, Gutiérrez 1995, Pacheco 1995, Andres et al. 2002).

El concepto de madurez tiene relevancia en cualquier programa de mejoramiento genético, tanto en el esquema de reproducción sexual, al determinar el momento para producción de semilla y polen para cruzamientos controla- 
dos, como también en la etapa de propagación vegetativa, en que los procesos de envejecimiento dificultan el enraizamiento del material seleccionado para la continuidad del ciclo, hecho que ha sido demostrado para coníferas de alta importancia económica tales como Pinus radiata D. Don, Pinus taeda L., Pseudotsuga menziesii (Mirb.) Franco, Picea abies L. Karst, entre otras (Gutiérrez 1995, Von Aderkas y Bonga 2000, Prehn et al. 2003).

La propagación asexual mantiene los caracteres maternos en la descendencia, aspecto de gran utilidad en el ciclo de mejoramiento y en la planificación silvicultural, al obtener material valioso para aumentar el rendimiento de las masas boscosas, logrando la captura de la ganancia genética aditiva y no aditiva (Muñoz 1997). Actualmente la organogénesis y especialmente la embriogénesis somática constituyen los métodos de propagación de mayor productividad y potencialidad para ser aplicados como herramientas biotecnológicas, permitiendo integrar la transformación genética al cultivo forestal (Prehn et al. 2003, Schestibratov et al. 2003).

No obstante, la introducción de material in vitro ha sido restringida por el efecto de la edad de la planta donadora (Franclet et al. 1987, Hartmann y Kester 1987, Von Aderkas y Bonga 2000), surgiendo la necesidad de conocer en mayor detalle los factores que determinan la calidad óptima del explanto seleccionado para iniciar un proceso de cultivo in vitro y su asociación con la madurez del mismo. Así, el objetivo del estudio es establecer una relación entre la fuente de extracción del explanto, esto es, su ubicación dentro del árbol donador, y la respuesta del material embrionario en condiciones de cultivo in vitro, evaluando la condición fisiológica asociada.

\section{MÉTODOS}

Material vegetal. El material vegetal fue extraído de un rodal de $P$. radiata de 15 años ubicado en la estación experimental La Cantera y El Guindo, propiedad de la Universidad de Concepción ( $36^{\circ} 46^{\prime}$ S y $73^{\circ} 03^{\prime} \mathrm{O}$ ), Región del Biobío, Chile. Dicho material fue recolectado a fines de invierno del año 2004, seleccionando aleatoriamente cinco árboles, desde donde se extrajeron conos maduros a distintas alturas. La altura total del árbol fue dividida en tres zonas: basal (0-4 m), media (4,1-12 m) y apical (12,1-18 m). Se extrajeron cinco conos de cada zona, completamente lignificados, de aspecto sano y color café oscuro. La morfología de los conos fue idéntica para las tres zonas muestreadas. Los conos colectados fueron disectados con una sierra de calar y las semillas se extrajeron en forma manual, seleccionando aquellas con un calibre promedio de $7 \mathrm{~mm}$, textura lisa y color negro.

Introducción in vitro. Se realizó una asepsia superficial de las semillas en cámara de flujo laminar utilizando etanol al $70 \%$ durante cinco minutos en agitación, con tres la- vados en agua destilada estéril por cinco minutos, según lo descrito por Aitken et al. (1981) y Pacheco (1995). Posteriormente, las semillas fueron sumergidas en una solución de hipoclorito de sodio al 50\% v/v, durante 20 minutos en agitación, seguido de tres enjuagues en agua destilada estéril por 5, 10 y 15 minutos, respectivamente. Bajo lupa, se escindió la cubierta seminal, se eliminó el endosperma y se introdujo el embrión maduro en tubos de ensayo que contenían $15 \mathrm{~mL}$ de medio de cultivo sólido. El medio de cultivo utilizado correspondió a QL formulado por Quorin y Lepoivre (1977), con reducción de los macronutrientes a $1 / 4$, y adición de reguladores del crecimiento $(4,4 \mu \mathrm{M}$ BAP y $0,5 \mu \mathrm{M}$ AIB). El medio de cultivo fue suplementado con $30 \mathrm{~g} \mathrm{~L}^{-1}$ de sacarosa y $7 \mathrm{~g} \mathrm{~L}^{-1}$ de agar. El pH fue ajustado a 5,8 previa inclusión del agar y esterilizado en autoclave a $120^{\circ} \mathrm{C}$ y 1 atm de presión durante 20 minutos. Luego de la siembra, los embriones se mantuvieron en oscuridad durante siete días a una temperatura ambiente de $25 \pm 1^{\circ} \mathrm{C}$ y humedad relativa del $60 \%$ y posteriormente fueron trasladados a cámara de crecimiento con ambiente controlado a $25 \pm 1^{\circ} \mathrm{C}$ de temperatura ambiente, humedad relativa del $60 \%$ y un fotoperíodo de $16 \mathrm{~h}$, con una intensidad lumínica de $40 \mu \mathrm{mol} \mathrm{m} \mathrm{m}^{-2} \mathrm{~s}^{-1}$.

Análisis estadístico. A los datos obtenidos se aplicó un análisis de varianza (ANDEVA) para muestras no balanceadas, evaluando como variables dependientes la germinación $(\%)$, supervivencia $(\%)$, número de yemas laterales y altura de microtallos (mm). Las diferencias significativas fueron determinadas utilizando la prueba de comparación de medias de Tukey, con un nivel de significancia del $5 \%$.

\section{RESULTADOS}

Luego de 45 y 60 días de cultivo los embriones obtenidos desde las zonas media y basal del árbol lograron elevadas tasas de germinación y supervivencia, respectivamente, superiores al $80 \%$. En cambio, embriones obtenidos desde la zona apical presentaron menores tasas de germinación, que se corresponden con la observación de un retraso en el crecimiento y elongación de los ejes embrionales, sin cambios en aspectos morfológicos de forma, color o textura. Sin embargo, estos no supervivieron luego de 60 días de cultivo (cuadro 1).

En efecto, ejes embrionarios extraídos desde la zona apical no mostraron crecimiento a los 15 días de cultivo, presentando sólo un leve aumento de tamaño, aspecto distintivo en las etapas tempranas de germinación de embriones zigóticos, lo que según Yeung et al. (1998) se asocia al incremento en los niveles de almidón en las zonas polares del embrión (figura 1A). Sin embargo, en ejes embrionarios procedentes de las zonas media y basal (figuras 1B y 1C, respectivamente) mostraron una evidente elongación y desarrollo de epicotilo. 
Cuadro 1. Germinación de embriones zigóticos maduros de Pinus radiata después de 45 días y supervivencia de embriones germinados a los 60 días de cultivo in vitro en medio QL (letras iguales indican que no existe diferencia significativa, $P>0,05)$.

Germination of mature zygotic embryos of Pinus radiata after 45 days and survival of germinated embryos at 60 days of in vitro culture in QL medium (same letters indicate that there is no significant difference, $P>0.05$ ).

\begin{tabular}{lccc}
\hline $\begin{array}{l}\text { Zona del } \\
\text { árbol }\end{array}$ & $\begin{array}{c}\mathrm{N}^{\text {o embriones }} \\
\text { iniciales en } \\
\text { cultivo }\end{array}$ & $\begin{array}{c}\text { Germinación } \\
(\%)\end{array}$ & $\begin{array}{c}\text { Supervivencia } \\
(\%)\end{array}$ \\
\hline Apical & 90 & $5 \pm 1,2 \mathrm{a}$ & $0 \pm 0 \mathrm{a}$ \\
Media & 86 & $85 \pm 36,6 \mathrm{~b}$ & $80 \pm 39,2 \mathrm{~b}$ \\
Basal & 80 & $95 \pm 22,4 \mathrm{~b}$ & $100 \pm 0 \mathrm{~b}$ \\
\hline
\end{tabular}

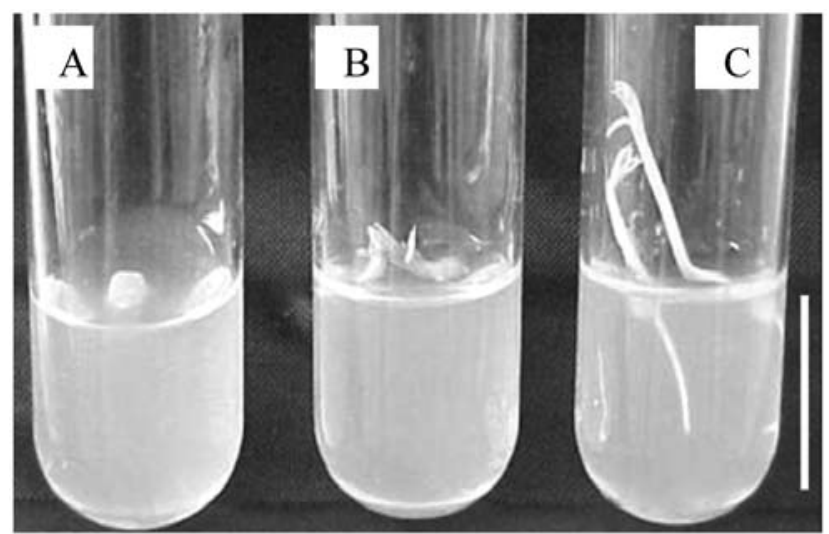

Figura 1. Secuencia de establecimiento de ejes embrionarios maduros de Pinus radiata: A) embrión de zona apical del árbol, B) embrión de zona media del árbol y C) embrión de zona basal del árbol, a los 15 días de cultivo in vitro. Barra: $1 \mathrm{~cm}$.

Microplantlet establishment sequence from mature embryos in Pinus radiata: A) apical zone embryo, B) medial zone embryo and C) embryo from the basal zone of the tree, at day 15 of in vitro culture. Bar: $1 \mathrm{~cm}$.

Una vez iniciada la fase de multiplicación, el número de yemas laterales (figura 2A) y la elongación de microtallos (figura 2B) fueron mayores en el material vegetal obtenido desde ejes embrionarios procedentes de la zona basal. Fue en estos microtallos donde se obtuvo la mayor formación de nuevos brotes, asociándose a un mayor vigor respecto de los microtallos originados de ejes embrionarios procedentes de la zona media del árbol, lo que en la fase de elongación caulinar se traduce en acículas de tono verde oscuro, de apariencia más gruesa y compacta en la base de los microtallos originados.

En la etapa de elongación se cuantificó la generación de callo organogénico de apariencia compacta, color café oscuro y tamaño uniforme en la base de los microtallos, observándose que en aquellos microtallos originados a

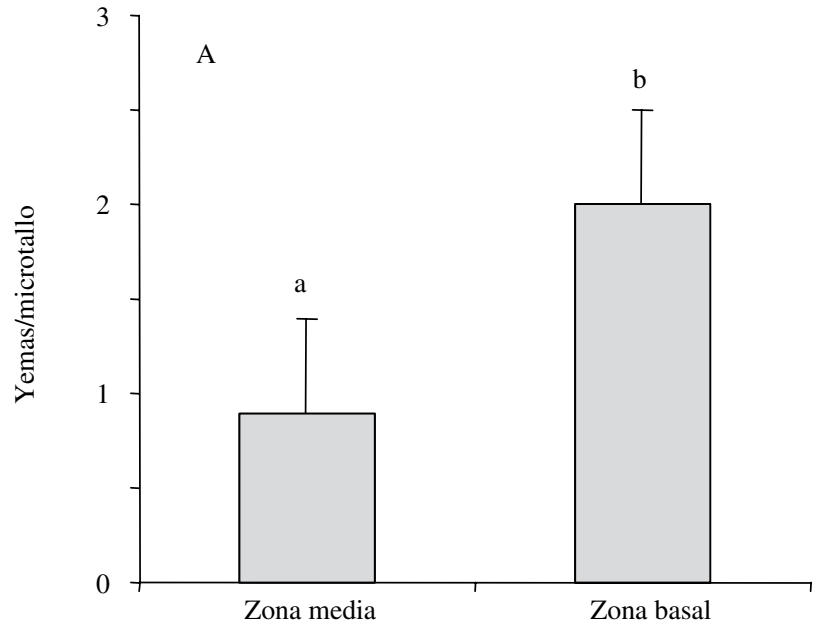

Origen embrión maduro

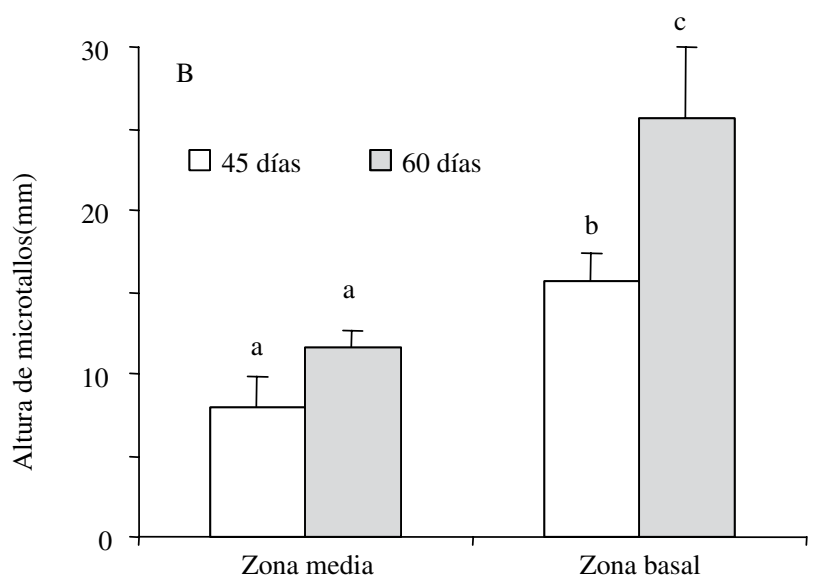

Figura 2. Número de yemas laterales (A) y altura de microtallos (B) después de 60 días en microtallos provenientes de embriones maduros extraídos desde las zonas media y basal en árboles de Pinus radiata $(\mathrm{n}=86$ embriones y 80 embriones respectivamente en etapa de introducción, letras iguales indican que no existe diferencia significativa, $P>0,05)$.

Number of lateral buds (A) and microshoots height (B) after 60 days, in microshoots of mature embryos extracted from the medial and basal zones of Pinus radiata trees $(\mathrm{n}=86$ and 80 embryos respectively in the introduction phase, equal letters indicate that there is no significant difference, $P>0.05$ ).

partir de ejes embrionarios procedentes de la zona media del árbol, la callogénesis fue superior (45\%) a la observada en microtallos originados de ejes embrionarios provenientes de la zona basal del árbol (5\%). Adicionalmente, se observó que un $15 \%$ de estos microtallos manifestaron formación de raíces adventicias.

\section{DISCUSIÓN}

La edad ontogénica varía de acuerdo a la posición del material vegetal en el árbol (Magini 1984). Sin embargo, 
la edad ontogénica de los embriones utilizados en este estudio es idéntica para las distintas zonas de extracción, ya que son producto de reversiones meióticas que generaron a los gametos formadores del zigoto. Las diferencias de ontogenia se encuentran en los tejidos donde se originan los conos y esto puede estar relacionado a los resultados observados en los ejes embrionarios procedentes de la zona apical, cuyos tejidos sobre los cuales se forman las estructuras reproductivas presentan una mayor madurez ontogénica en comparación a aquellos que rodean a las semillas ubicadas en posiciones distales al ápice (Franclet $e t$ al.1987, Yeung et al. 1998, Hasbún et al. 2005). Al respecto, la respuesta observada en los ejes embrionarios de origen apical podría estar asociada a lo observado por Spicer y Gartner (2001) en Pseudotsuga menziesii en cuanto a que la mayor edad del xilema afecta la resistencia al flujo del agua en la parte superior del árbol, aspecto que influye en los parámetros físicos de tejidos ubicados en esta zona, lo que podría estar retrasando el proceso de fructificación de conos ubicados en esa zona del árbol y los embriones no logren una madurez completa al mismo tiempo de aquellos ubicados en conos de otra zona del árbol. Sin embargo, es probable que las diferencias observadas se deban también a diferencias en el tipo y concentración de hormonas en las semillas de las diferentes alturas en el árbol, cuestión no probada en este estudio y que podría ser abordada en futuras investigaciones.

La mayor capacidad morfogénica mostrada por los embriones obtenidos desde conos ubicados en las zonas media y basal de la copa concuerda con estudios realizados por Fouret et al. (1986), Thanh et al. (1987) y Yeung et al. (1998), quienes informan una mayor competencia morfogénica en microtallos basales y mejor utilización de las reservas nutritivas para la elongación celular, a diferencia de lo que ocurre en los microtallos intermedios, en donde se redistribuyen los nutrientes para estimular la altura del microtallo.

En este estudio, el hecho de obtener material de ambas edades fisiológicas resulta en una diferencia de la calidad del individuo producido y posiblemente en la habilidad para revitalizar el crecimiento de nuevos puntos meristemáticos (Fouret et al. 1986, Pacheco 1995, Von Aderkas y Bonga 2000). La mejor respuesta en elongación del material proveniente de la zona basal estaría asociada a la mejor condición fisiológica de los tejidos formadores de la semilla en conjunto con su proximidad espacial cercana a la base del tronco (Pierik 1990). Al respecto, Thanh et al. (1987), en un estudio de desarrollo de conos masculinos en explantos nodales de uno a $12 \mathrm{~cm}$ de rebrotes de tocón en Sequoia sempervirens (D. Don) Endl., demostraron que además del positivo efecto de la zona basal de extracción de explantos se observó un efecto del tiempo de colecta, al obtener menores tasas de desarrollo de yemas axilares en épocas cercanas a la estación estival. Otros ejemplos que avalan el efecto de la posición en el árbol donador son los realizados por Prehn et al. (2003), Schestibratov et al. (2003) y Tang et al. (2004), quienes utilizando brotes epicórmicos sugieren que la estabilidad de las características juveniles se conserva una vez iniciado un proceso de reproducción vegetativa y el potencial de iniciación de raíces adventicias sería uno de estos elementos en que la retención de la habilidad de enraizar y otras características juveniles está relacionada a la posición en el árbol y su condición ontogénica.

Aunque se han verificado marcadas diferencias en la respuesta en los parámetros de multiplicación de microtallos al cultivo in vitro dependiendo de su posición en el árbol, es necesario incluir otras evaluaciones para aislar el efecto de la madurez propia de la semilla como, por ejemplo, pruebas de germinación de semilla extraída a diferentes alturas. Por otra parte, las diferencias en la respuesta a la proliferación y elongación de estos tres tipos de explantos podrían estar vinculadas a la existencia de marcadores de tipo bioquímico o diferencias en concentraciones hormonales como lo sugieren Von Aderkas y Bonga (2000), Andres et al. (2002), Fraga et al. (2002), Tang et al. (2004) y Ramarosandratanam y Van Staden (2005), ya que las distintas fases de desarrollo se expresan a través de mecanismos cuantificables a distintos niveles de actividad metabólica, de acuerdo al desarrollo de los mismos (Hasbún 2006). Por ello, sería útil abordar el tema de la caracterización bioquímica del material, para evaluar el seguimiento de la respuesta in vitro de los microtallos en subcultivos sucesivos, técnicas de enraizamiento o utilización en microinjerto, como futuras aplicaciones.

\section{CONCLUSIONES}

La técnica de micropropagación posibilita la reactivación metabólica embrionaria al proporcionar las condiciones óptimas de germinación, proliferación y elongación de microtallos provenientes de explantos embrionales de zonas intermedias y basales, logrando contrarrestar el efecto de la madurez fisiológica de los tejidos formadores maternos circundantes, que siguen siendo menos envejecidos que aquellos ubicados en la zona apical. La utilidad práctica del método es establecer la posición de conos dentro del árbol que permita, a partir de árboles adultos con expresión total del genotipo, introducir material para iniciar el ciclo de embriogénesis somática, etapa clave en un programa de multiplicación de individuos elite a gran escala.

\section{REFERENCIAS}

Aitken J, K Horgan, T Thorpe. 1981. Influence of explant selection on the shoot-forming capacity of juvenile tissue of Pinus radiata D. Don. Canadian Journal of Forest Research 11: 112-117.

Andres H, B Fernández, R Rodríguez. 2002. Phytohormone contents in Corylus avellana L. and their relationship to age and other developmental processes. Plant Cell, Tissue and Organ Culture 70 (2): 173-180. 
Borja L, M Berdasco, M Fraga, M Cañal, R Rodríguez, C Castresana. 2004. A Pinus radiata AAA-ATPase, the expression of wish increases with tree ageing. Journal of Experimental Botany 55: 1597-1599.

Fouret Y, Y Arnaud, C Larrieu, E Miginiac. 1986. Sequoia sempervirens (D. Don) Endl. as an in vitro rejuvenation model. New Zealand Journal of Forestry Science 16 (3): 319-327.

Fraga M, M Canal, R Rodríguez. 2002. In vitro morphogenic potential of differently aged Pinus radiata $\mathrm{D}$. Don trees correlates with polyamines and DNA methylation levels. Plant Cell, Tissue and Organ Culture 70 (2): 139-145.

Franclet A, M Boulay, F Bekkaqoui, Y Fouret, B Vershooremartouzet, N Walker. 1987. Rejuvenation. In Bonga J, D Durzan eds. Tissue culture in forestry. Dordrecht, The Netherlands. Martinus Nijhoff Publishers. p. 232-248.

Gutiérrez B. 1995. Consideraciones sobre la fisiología y el estado de madurez en el enraizamiento de estacas de especies forestales. Ciencia e Investigación Forestal 9(2): 261-276.

Hartmann H, D Kester. 1987. Propagación de plantas: principios y prácticas. México. Continental. $760 \mathrm{p}$.

Hasbún R, L Valledor, M Berdasco, E Santamaría, M Cañal, R Rodríguez, D Ríos, Sánchez M. 2005. In Vitro proliferation and genome DNA methylation in adult chesnuts. Acta Horticulturae 693: 333-340.

Hasbún R. 2006. Monitorización (epi)-genética del desarrollo y producción de plantas de castaño (Castanea sativa). Tesis Doctor. Oviedo, España. Universidad de Oviedo. 234 p.

Magini E. 1984. Il ringiovanimento del materiale forestale di propagazione. In azienda regionalle delle Foreste (Ed). Propagazione in vitro: Ricerche su alune specie forestales (s/e). Italia. (irreg.page)

Muñoz M. 1997. Efecto del número de hojas y concentración de ácido indolbutírico en el enraizamiento de estaquillas de Eucalyptus globulus Labill. Tesis Ingeniero Forestal. Concepción, Chile. Facultad de Ciencias Forestales, Universidad de Concepción. 150 p.

Quorin M, P Lepoivre. 1977. Etudes de mileux adaptes aux cultures in vitro de prunes. Acta Horticulturae 78: 437-442.
Pacheco J. 1995. Revigorización de material adulto de Pinus nigra Arn.: criterios morfológicos y moleculares. Tesis Doctor. Oviedo, España. Departamento de Biología de Organismos y Sistemas, Universidad de Oviedo. 1995. 200 p.

Pierik R. 1990. Cultivo in vitro de las plantas superiores. Madrid, España. Multiprensa. 326 p.

Prehn D, C Serrano, A Mercado, C Stange, L Barrales, P ArceJohnson. 2003. Regeneration of whole plant from apical meristems of Pinus radiata. Plant Cell, Tissue and Organ Culture 73(1): 91-94.

Ramarosandratanam A, J Van Staden. 2005. Changes in competence for somatic embryogenesis in Norway spruce zygotic embryo segments. Journal of plant Physiology. 162: 583-588.

Russell J, S Grossnickle, C Ferguson, D Carson. 1990. Yellow cedar stecklings: nursery production and field performance. Victoria, British Columbia. Ministry of Forests, FRDA Report $\mathrm{N}^{\circ} 148$.

Schestibratov K, R Mikhailov, S Dolgov. 2003. Plantlet regeneration from subculturable nodular callus of Pinus radiata D. Don. Plant Cell, Tissue and Organ Culture 72(2): 139-146.

Spicer R, B Gartner. 2001. The effects of cambial age and position within the stem on specific conductivity in Pseudotsuga menziesii (Mirb.) Franco sapwood. Trees, Structure and Function 15(4): 222-229.

Tang W, L Harris, C Outhavong, R Newton. 2004. The effect of different plant growth regulators on adventitious shoot formation from Pinus virginiana Mill. zygotic embryo explants. Plant Cell, Tissue and Organ Culture 78(3): 237-240.

Thanh T, D Yilmaz, T Trinh. 1987. In vitro control of morphogenesis in conifers. In Bonga J, D Durzan. Tissue culture in forestry. Dordrecht. The Netherlands. Martinus Nijhoff Publishers. p. 168-182.

Von Aderkas P, J Bonga. 2000. Influencing micropropagation and somatic embryogenesis in mature trees by manipulation of phase change, stress and culture environment. Tree Physiology 20: 921-928.

Yeung E, C Stasolla, L Kong. 1998. Apical meristem formation during zygotic embryo development of white spruce. Canadian Journal of Botany 76: 751-761. 